\title{
ATOR DE SUA TRAJETÓRIA PROFISSIONAL?
}

\author{
Geneviève Dahan-Seltzer
}

\begin{abstract}
RESUMO
Este artigo consiste numa síntese de nossos cursos oferecidos nos cursos de formação continuada do Instituto de Estudos Políticos e da Universidade de Paris, Dauphine, nos quais mobilizamos um conhecimento sociológico que nos permite munir os próprios atores analisados - participantes da pesquisa - com as ferramentas analíticas necessárias para encontrar respostas aos problemas de sua trajetória profissional. Primeiramente, apresentamos a constatação de fatos que nos conduzem àquele método : buscamos apresentar o contexto de crise (dos modelos de identificação, dos vínculos sociais e das instituições e da socialização) no qual se inserem atores e empresas. A partir dessa constatação, mobilizamos um conhecimento sociológico, baseado na teoria do ator e da reflexividade, para propor um projeto de pesquisa com fins práticos, de modo a fornecer aos atores em crise as ferramentas necessárias para sua superação, por meio de uma auto-análise, especialmente de sua trajetória e do contexto profissionais no qual evolui. Finalizamos o artigo discutindo esse aspecto aplicado, defendendo a necessidade de uma postura sociológica ao mesmo tempo clínica e crítica.
\end{abstract}

PALAVRAS-CHAVE: identidades; crise; reflexividade; atores; trajetória profissional; empresas.

\section{INTRODUÇÃO: AS TRAJETÓRIAS DOS IN- DIVÍDUOS E DAS EMPRESAS}

Durante os últimos anos, nos cursos de formação continuada do Instituto de Estudos Políticos e da Universidade de Paris, Dauphine, tenho buscado desenvolver as capacidades de análise e de reflexividade dos indivíduos acerca de modos de regulação das empresas em transformação, por meio de grupos de análise de práticas, de entrevistas individuais e de grupo. A tese que desenvolvo nesses programas é que, no mundo atual, os indivíduos vivenciam um sentimento de vertigem, de perda de sentidos e ficam em busca de marcos de referência, em busca de redes e recursos, como que em um "movimento perpétuo".

O fenômeno perturbador, neste caso, é que a trajetória das empresas e dos indivíduos podem ser paralelas, ou seja, ir no mesmo sentido durante algum tempo, mas depois tornarem-se, de repente, muito antagônicas. Ou seja, as trajetórias profissionais não são mais tão ascensionais e previsíveis quanto costumavam ser. Cabe a cada um fazer um esforço de reflexividade e analisar os contextos nos quais ele evolui para construir sua trajetória profissional, sob pena de recesso, senão de rejeição, com todas as conseqüências que isso envolve no percurso de vida.

O título deste artigo é "Ator de sua trajetória profissional?”. Contudo, ser ator de sua trajetória é uma injunção da atualidade nas empresas e na sociedade, não se explicando isoladamente. Antes, esse processo envolve muitas perguntas e requer condições específicas para o seu desdobramento, fazendo que o ponto de interrogação no título revele toda a importância do tema.

Depois de examinar alguns aspectos introdutórios a essa temática a seguir, apresentarei, na seção de número três, o que observo com tipos de trajetórias profissionais dos indivíduos nesse contexto de crise. Na quarta parte discuto o nosso programa pedagógico, ficando para a quinta e última uma reflexão dos desafios que este trabalho teórico e prático colocam para a Sociologia.

\section{CRISES DOS ATORES, DAS EMPRESAS E DA SOCIEDADE}

\section{II.1. As crises em pauta}

Para desenvolver esta reflexão, retomo, em primeiro lugar, algumas constatações sobre a crise da sociedade e das empresas, mais correntes na literatura sociológica contemporânea. A maior parte dos sociólogos concorda sobre o fato de que a sociedade está em crise, que há uma crise dos modelos de identificação, outra do vínculo social e ainda uma outra crise das instituições e da socialização.

Claude Dubar (2000), por exemplo, refere-se a algumas dimensões da crise contemporânea,

Rev. Sociol. Polít., Curitiba, v. 16, n. 31, p. 25-33, nov. 2008 
como a crise das identidades simbólicas, que se manifesta pelo descrédito das instituições intermediárias e a crise das próprias identidades sexuais relacionadas a novas dinâmicas familiares. Já Alain Ehrenberg (1998) analisa as crises de identidade pessoal, e aponta para o cansaço de ser simesmo em um mundo em que é necessário desempenhar o tempo todo, sempre submetendo-se a provas da escola, do trabalho, da família, etc. Mas há também as crises das regulamentações na empresa e crise das identidades profissionais. Os mundos da empresa são o lugar de fortes desregulamentações, devido aos processos de modernização em instalação para responder às exigências do mercado.

As transformações do trabalho foram amplamente descritas, bem como as situações de crise e de mal-estar que elas geram. Nesse âmbito, a regulação institucional libera-se da regulação produtiva. Com efeito, os "modelos produtivos" que definiam, ao mesmo tempo, a organização da produção e do trabalho e a gestão dos empregos modificam-se intensamente em benefício de uma flexibilidade e de uma responsabilização maior dos indivíduos. Novas organizações desestabilizam as relações anteriores, novas práticas de gestão do emprego emergem e, além disso, assiste-se a uma redistribuição das posições de poder entre velhos e novos assalariados, assim como entre funções. As fusões sucessivas confundem os pertencimentos e produzem uma desfiliação, e as identificações nos coletivos tornam-se problemáticas. As identidades profissionais são desestabilizadas.

Nessas situações de crises, as organizações e os atores como que também põem à prova o discurso e as normas. Desvios crescentes entre os discursos e as práticas induzem a uma exposição mais forte dos atores individuais e coletivos em todos os níveis. Os atores e as organizações passam a enfrentar uma intensificação de paradoxos e suas relações tornam-se confusas (CROZIER \& FRIEDBERG, 1977).

Há, por exemplo, o paradoxo da injunção e da participação, ou seja, entre uma ideologia gerencial funcionando à injunção, exaltando a participação e uma redução de fato dos espaços coletivos de debates. Capacidades de cooperação aparecem, portanto, mais como os temas-chave para o futuro da empresa. Por outro lado, a estratégia econômica, a organização do trabalho e o futuro das funções freqüentemente ficam fora do debate.
Além desse, existe o paradoxo da responsabilização e do maior controle. Apesar dos discursos correntemente assumidos, atores como diretores de entidades fazem freqüentemente a constatação de uma redução de suas margens de manobra e de um fraco acesso à dimensão política e estratégica da empresa ou do grupo, enquanto o controle de resultados aumenta.

Há também o paradoxo do vínculo virtual e do vínculo físico. Os gerentes, em sua busca de eficiência, absorvidos pela multiplicação das normas e das ferramentas de gestão, podem ir ao encontro da eficácia pesquisada, portadores da cultura da empresa, acarretando uma perda do sentido do trabalho.

Por último, existe ainda o paradoxo da solidariedade e do individualismo. As solidariedades são colocadas à prova pelo deslocamento das identidades coletivas. A pessoa ressente-se por uma vivência de perda dos identificadores coletivos anteriores: a função, o estrato, o pertencimento local e o sindicato. Sobressai-se uma reflexão sobre si, por meio da qual o indivíduo compreende que cabe a cada um construir-se e que ele precisa ter o sentido do coletivo e da cooperação, mas também seguir seu interesse individual para fazer carreira ou para salvaguardar seu emprego.

\section{II.2. Indivíduos e atores}

De fato, como pude recuperar recentemente por meio de uma entrevista cruzada com Eugène Enriquez e Robert Castel, há um aprofundamento desse processo de individualização das relações sociais com os mais variados efeitos (CASTEL \& ENRIQUEZ, 2008).

A partir da hipótese de que "nós estamos nos processos de descoletivização do trabalho”, Robert Castel afirma que "se o capitalismo industrial pôde conhecer formas de organização e de proteção coletivas, há hoje uma descoletivização, o que quer dizer que o trabalhador é interpelador para enfrentar situações, para ser capaz de assumir a mudança, para mostrar iniciativa (CASTEL \& ENRIQUEZ, 2008, p. 24).

Por outro lado, ele, contudo salienta: "Atrás dessas práticas, há efetivamente um processo de individualização, poder-se-ia dizer de descoletivização ou de dessocialização, no sentido em que social não é mais percebido como uma referência externa, por exemplo segundo a concepção clássica do social de Durkheim” (CASTEL 
\& ENRIQUEZ, 2008, p. 17). E complementa: « Há uma espécie de reinterpretação do social como sendo do psicológico no sentido de relacional da rede, dos grupos, da colocação em destaque do grupo. Trata-se de um coletivo descoletivizado, que se limita ao interrelacional. Nessas condições, as restrições vinculadas à estrutura social não são pensadas, não são levadas em conta, e o social torna-se sociabilidade" (CASTEL \& ENRIQUEZ, 2008, p. 17).

O que acontece com os atores nesse contexto e como analisá-los? Que categorias empregar? O mesmo Robert Castel sustenta que desde o século XIX é a responsabilidade do indivíduo que está no centro: "Pode haver um reconhecimento forte da autonomia do indivíduo, ao ponto de fazer da responsabilidade o valor preponderante, mas não é a subjetividade do indivíduo, é o personagem social que é ressaltado" (CASTEL \& ENRIQUEZ, 2008, p. 19).

Já Eugène Enriquez, por sua vez, lembra-nos que, "durante muito tempo, será dito que o indivíduo era importante mas sempre levando em conta sua inserção de classe, sua inscrição nas relações de produção. Em toda uma parte do pensamento marxista, o homem era simplesmente o reflexo das relações de produção das relações de classe. Seu papel ficava condicionado, determinado pelo lugar que ele ocupava nos processos de produção.”(CASTEL \& ENRIQUEZ, 2008, p. 18). O agente agia pela organização ou ele era encarregado de uma função. Em matéria de carreira, o avanço na idade regula as etapas que são préestabelecidas em um espaço limitado, no quadro de um estatuto protetor (DAHAN-SELTZER, 2008).

Crozier denomina o indivíduo atual como um “ator estratégia” (CROIZER, 1977). Assim, ele se situa em um quadro de restrições, ainda que tenha uma margem de manobra, se souber utilizá-la. Ele não é completamente determinado, e ambiciona, firme em sua racionalidade e sua visão estratégica, uma matriz de seu futuro, ele espera construir seu futuro em função das oportunidades e de seus interesses. É o ator estratégia dos anos de crescimento, mas o ator estratégia podia apoiar-se em alianças e numerosos recursos internos que não são também mais pertinentes ao contexto atual.

Nessa dinâmica, explica Eugène Enriquez, “a resposta ao ator de classe e ao ator racional veio com Freud quando as pessoas perceberam que essas sociedades que se transformavam acarretavam muitos problemas psicológicos, como mostrou Durkheim em “O suicídio”. Traz-se então uma atenção ao indivíduo como tal, não simplesmente ao indivíduo racional, tendo sua liberdade e seu divertimento, mas à complexidade de sua vida psíquica e às conseqüências que ela pode ter sobre o modo de funcionamento social" (CASTEL \& ENRIQUEZ, 2008, p. 19). Frente às incertezas do momento atual, o indivíduo passa por muito estresse e sofrimento no trabalho.

Enfim, entende-se agora o indivíduo como ator de si como de um empreendedor de si, tendo a capacidade de gerir seu corpo, suas aparências, suas emoções, suas identidades plurais e seus pertencimentos múltiplos, visando produzir a si mesmo tanto quanto possível. Senão, prossegue Eugène Enriquez, ele seria o "indivíduo padrão" de Robert Castel "que eu chamarei de homem precário", precário em tudo: "ele não sabe o que se tornarão seus filhos, ele não sabe se não vão tomar-lhe a casa (como nos Estados Unidos), ele não sabe se seu marido ou sua mulher não vai deixá-lo de uma hora para outra... Fica-se numa espécie de precariedade generalizada das relações sociais, que já toca muitos estratos, mas tocará cada vez mais pessoas situadas também em níveis elevados" (CASTEL \& ENRIQUEZ, 2008, p. 25). Nós estaríamos assim numa sociedade profundamente atravessada por processos de desestabilização.

Como o indivíduo pode enfrentar todas essas crises? Tornando-se um indivíduo reflexivo, como ensina Anthony Giddens por meio da noção de reflexividade. Para Giddens (1994), a reflexividade é uma exigência social voltada para a ação com resultados (diferente da introspecção), um discurso sobre a atividade, um elemento da ação, ora induzido, ora instituído.

Com efeito, as práticas sociais não podem mais legitimar-se pelo apelo à tradição, elas precisam de uma apropriação reflexiva da mudança. Tratase então de construir-se estabelecendo o indivíduo mesmo os vínculos entre a sua experiência individual e a mudança social, em um vai e vem constante. A identidade é então o fruto de uma auto-reflexividade, graças à qual o indivíduo consegue manter uma narração sobre si. A condição moderna restringe os indivíduos a transformaremse por meio de um projeto reflexivo. Pela produção de uma narrativa sobre si, a pessoa torna-se, 
portanto, um projeto explícito permanente, de construção da confiança, de construção das relações e das redes. A reflexividade é um elemento da condição moderna, tomada de si, dever de ser a si mesmo, capacidade de ação ou retirada... ela é uma tomada de distância cultural, uma competência crítica perante a si mesmo.

Nesses termos, o indivíduo torna-se um ator no centro de sua própria vida, cabendo a ele hoje construir sua coerência, dar sentido a sua existência, em um mundo em explosão, do que deriva importância acordada nas estratégias de identidade correlativas ao desenvolvimento da "luta de lugares” (GAULEJAC, 1994). A partir do momento em que o lugar de cada um não é mais designado a priori, cada indivíduo tem a liberdade de mudá-la, nas também o risco de perdê-la. Também aumentam as tensões entre identidades herdadas (nascimento, origens sociais) e identidades adquiridas, atribuídas (vinculada à posição sócio-profissional) ou esperadas, às quais se aspira para ser reconhecido.

O indivíduo é a soma de construir-se frente ao esfarelamento das categorias, às instituições que não dão mais o sentido, apoiando-se em sua experiência e em sua subjetividade. O indivíduo está no centro de sua própria vida, diz Jean-Claude Kaufman (2006), mas tem de "fazer suas escolhas e pagar o preço, ele não é de lugar nenhum, mas ele é ligado a vários grupos, pertence a vários lugares e cabe a ele colar os pedaços do quebra-cabeça para que sua vida tenha um sentido e uma coerência.” A identidade envolve assim um trabalho e um processo de reflexão permanente, o indivíduo deve ser o ator ou o autor de sua própria vida.

Mais do que isso, o indivíduo acaba sendo forjado pela prova. Para Danilo Martucelli (2006), ser um indivíduo tornou-se o horizonte de nossas percepções da vida social. Cada um dentre nós forja-se por meio de uma série de provas, segundo modalidades inéditas. Essas provas desigualmente declinadas são enfrentadas para o essencial individualmente, mas o percurso de vida, da escola à família, do trabalho à cidade, da história à intimidade, não é menos profundamente coletivo. A lição que se tira disso é que a compreensão de si passa de uma maneira mais decisiva que nunca pela inteligência da sociedade.

A experiência social, para F. Dubet (1994), envolve arbitragens permanentes da parte do su- jeito entre diversos registros e diferentes lógicas em curso. O indivíduo torna-se o ator de sua trajetória, cabe a ele saber analisá-la, teorizá-la, projetá-la e apresentá-la. Trata-se, enfim, de um indivíduo hipermoderno, que, segundo Nicole Auber (2004) é multi-pertencente. Ele pode ocupar simultaneamente ou cronologicamente posições diversas, status diferentes e representar papéis sociais múltiplos. É preciso, portanto, que "ele efetue constantemente um trabalho sobre si mesmo para reencontrar nessa diversidade, posições ocupadas e atributos de identidade que elas contêm, uma coerência, uma unidade, uma permanência...”.

\section{A TRAJETÓRIA INTRANQÜILA E UMA EXPERIÊNCIA PEDAGÓGICA}

\section{III.1. A trajetória profissional e a crise}

Assim, a formação vai aparecer como lugar transitório de construção de identidade. As demandas de escuta, de reconhecimento de imagem, de apoio do indivíduo e de ajuda na análise de práticas em grupo de pares multiplicam-se nos cursos de formação contínua, local em que vem a adquirir-se competências, recursos e redes. As formações de longa duração constituem-se em uma ocasião de aprendizagens culturais múltiplas; elas constituem espaços transitórios que podem ser fonte de construção de identidade. E o indivíduo, nesse caso, é confrontado em um nível tríplice.

No nível cognitivo, ele é confrontado com o aprendizado de novos saberes que recolocam em questão seus saberes e seus modos de raciocínio anteriores. Já no nível social, o indivíduo é confrontado com as normas e com os valores que se elaboram no grupo por meio das interações individuais e coletivas. Ele ganha novas identificações, pela experiência grupal a que atravessa, nas apostas que faz. Mais do que isso, ele é confrontado com as diferenças entre esse lugar de socialização e seus locais habituais. Por outro lado, no nível profissional, ele é testado em sua capacidade de transferir as aquisições da experiência de formação na situação profissional e/ou na sua capacidade de formular um novo projeto, a dar uma orientação nova a sua trajetória. A formação contínua torna-se assim um espaço transitório de reflexividade para o indivíduo.

\section{III.2. Uma experiência pedagógica de análise da trajetória profissional: uma prática de reflexividade}




\section{III.2.1. Os objetivos}

Na equipe pedagógica de formação continuada do Instituo de Estudos Políticos, levamos em conta essas reflexões no mestrado «Diagnóstico social e estratégias de mudança». Dentro dos dois anos de formação, nós implementamos um módulo transverso, "Práticas profissionais da sociologia", que tem por objetivos:

- desenvolver uma competência de refletividade pela análise das práticas e das trajetórias profissionais;

- favorecer a integração ou a transferência das competências sociológicas adquiridas, no percurso profissional, pois é preciso visar uma apropriação suficiente para reincorporar esSa competência em uma posição profissional mais voltada para a ação;

- desconstruir uma postura que privilegie a análise baseada nas crenças, tentando fazer com que a formação na sociologia crie uma ruptura epistemológica com o senso comum, uma vez que essa reflexividade deveria constituir uma das bases da profissão de sociólogo, quer ele seja acadêmico ou profissional.

\section{III.2.2. O método}

O modulo é composto por três seqüências, no começo, no meio e no fim do ciclo. Ele deve dar lugar à redação de uma nota profissional que constitui um dos quatro elementos do dossiê de apoio para se chegar ao diploma.

O instrutor deve ajudar cada indivíduo em seu grupo a analisar sociologicamente a sua trajetória profissional, levando em conta a dinâmica do grupo. O grupo participa da função de análise e de reflexividade, sob o olhar do monitor. O que se espera é uma ajuda na análise das escolhas e mudanças engajadas, uma releitura da experiência, uma ajuda para a tomada de distância entre papel e indivíduo, uma ajuda para a construção de um projeto profissional.

As regras do jogo implantadas são confidenciais; há postura de escuta mútua e uma atitude de apoio não-avaliativa. O instrutor é o protetor do grupo, sustentando suas regras para que a elaboração individual e coletiva possa ser feita.

O projeto é produzir uma reflexão sobre si, mas também sobre a análise do contexto social. Trata-se de não posicionar o que aparece como uma disfunção do sistema e de não "sociologizar" a parte da equação pessoal, sendo que o que é mais freqüentemente analisado é:

- os determinantes sociais, familiares; experiências fundadoras nas escolhas profissionais;

- os processos pessoais de aprendizagem, de pesquisa, de emprego, de mobilidade e de construção de trajetória;

- a atualização dos referentes que são seus fundamentos: saberes teóricos, modelos de identificação, pertencimento;

- as razões explícitas e implícitas de sua escolha de formação;

- a confrontação e/ou a complementaridade da teoria sociológica e do método frente a aquisições anteriores;

- a atualização dos elementos fundamentais constitutivos de um projeto profissional ou de uma transferência possível na função atual;

- a análise dos recursos e das redes sociais.

\section{III.2.3. Resultados}

Assim, face aos imprevistos da trajetória, a sociologia não pode deixar de ser senão uma sociologia do imprevisível. Michel Grossetti (2004) trata das contingências que afetam os fenômenos sociais e os percursos de vida como um exemplo significativo disso, pois são tributários dos divórcios, das doenças, das perdas de emprego, entre outras. Trata-se, portanto, do indivíduo que busca sair da crise de mobilizar recursos cognitivos, relacionais, de mexer com as montagens segundo seus valores. E trata-se, para o sociólogo, ligado a analisar os fatos sociais, de propor novas categorias de análise.

Um acontecimento biográfico como um imprevisto dentro de um percurso profissional, tornando-se um acontecimento perturbador que provoca uma crise de identidade e afeta a trajetória, pode ser o gatilho de uma crise de si (perda de status, não-reconhecimento, bloqueio promocional, intensificação do trabalho, estafa, acontecimento familiar...). Nesse caso, agir-se-á de forma a aprender competências reconhecidas 
para revalorizar-se em relação à organização excludente, facilitar uma saída de crise para reparar um sofrimento psíquico e interrogar o local de trabalho na existência.

Por outro lado, qualquer prova é um desafio histórico, socialmente produzido, desigualmente distribuído, que os indivíduos são constrangidos a enfrentar, para ter êxito ou fracasso - vive-se com "a gramática das provas" (exames, concursos, aposentadoria etc.). Já o acidente (doença, divórcio ou outro) gera uma saída de sua trajetória prevista.

Uma bifurcação é, para ele, "um modo particular de articulação das imprevisibilidades. A bifurcação aparece como um operador prestando conta de deslocamento sobre as escalas de ação do micro para o macro, do tempo curto para o tempo longo, do especializado para o geral”. Já Georges Balandier (1988), refletindo a esse respeito, considera que "a idéia de bifurcação limita a empresa dos determinismos sociais, permite situar os pontos de liberdade, identificar os possíveis [...]. A seleção dos possíveis far-se-á sucessiva e progressivamente, da maneira como um percurso é efetuado de encruzilhada em encruzilhada, até chegar a um termo ainda desconhecido».

Na pós-modernidade, que ele define por seus dois termos "incerteza" e "movimento", os indivíduos tornam-se nômades como os objetos, eles são levados por uma trajetória e não mais se situam dentro de um trajeto linear, obrigando o sociólogo a sair dos quadros de análise deterministas e determinantes além de categorias como "nacionalidade, classe, gênero", concluindo que a experiência, enfim, forja mais que as categorias!

\section{TIPOS DE TRAJETÓRIAS E AS PERGUN- TAS PARA OS INDIVIDUOS}

Apresentarei agora alguns exemplos de tipos de trajetórias, resultantes de minhas reflexões e prática pedagógica, que são mais seletivas que representativas, visto que, essencialmente, eu não encontro atores potencialmente não desprovidos de recursos nem de redes.

De um lado, temos "trajetórias de mobilidade”. Nesse caso, as possibilidades são muitas, como: mobilidade vertical? Mobilidade horizontal? Mudança de profissão e/ou de setor e/ou de empresa? Se o modelo da mobilidade vertical permanece, ele não é mais dominante e ele coexiste com projetos de mobilidade horizontal permitindo mudar de profissão, de setor de produção ou de setor geográfico e, por vezes, permite mesmo mudar os três ao mesmo tempo, por exemplo.

De outro, observamos "trajetórias de profissão”. Aqui teríamos o que poderia ser caracterizado como o "cumprimento da obra" profissional. Quando a identidade é fundada sobre os saberes cognitivos e experimentais ligados a uma profissão, a formação esperada é a ativação da trajetória anterior por um aprofundamento na área específica ou numa área próxima (recursos humanos e formação, por exemplo). A formação constitui uma alavanca de mudança e contribui para fazer acontecer o indivíduo, que tem o sentimento de cumprir a sua obra, como os companheiros anteriores.

Além dessas, podemos observar "trajetórias de criação”. Trata-se, para alguns, de fazer um desvio, uma bifurcação, como a saída de uma grande empresa em nome de um projeto pessoal de criação de uma pequena ou média empresa. Trata-se freqüentemente de uma ruptura escolhida para a qual o indivíduo vai mobilizar seus recursos e suas redes, não sem angústia, mas tentado pela aventura. O tempo da formação permite freqüentemente ao indivíduo dar o salto.

Reconhecemos ainda o que pode ser visto como "trajetórias de comprometimentos pontuais ou não”. Essas são as opções encontradas, mesmo em cursos de alto nível, por indivíduos jovens que desejam fazer uma pausa em sua trajetória (que poderiam ser rapidamente ascensionais), em nome de uma pesquisa de sentido, tal como um compromisso de seis meses ou mais numa Missão dos Médicos sem Fronteiras, ou num trabalho inesperado. Tal iniciativa pode também ser vista em uma "pré-aposentadoria”, por exemplo.

Algumas outras configuram-se como "trajetórias de retirada”, que são aquelas devidas a perdas de status, a bloqueios provenientes de um acontecimento ou de um acidente, de um nãoreconhecimento ou de um esgotamento. Nesse caso, há conflito de identidade quando as tensões são fortes demais ou muito antagonistas entre a identidade visada e a identidade reconhecida ou quando os papéis propostos entrechoquem-se ou são vividos como regressivos.

Na configuração dessas trajetórias, os indivíduos, por sua vez, enfrentam uma série de per- 
guntas, como: trata-se de uma continuidade ou bifurcação? Vê-se bem, nos exemplos mostrados acima e por meio da experiência do ensinamento em formação continuada, que os indivíduos não podem mais fazer o impasse sobre a incontornável questão da continuidade ou da ruptura da trajetória. O modo de não se perder é escolher, de preferência, a sofrer quando os meios permitirem-no se dar os meios para isso; a formação sendo um dentre eles.

Por outro lado, há a questão do reconhecimento. A questão da identidade, tanto individual quanto coletiva, ressurge nessa fase de movimento perpétuo em que as antigas marcas são desestabilizadas; em que o sentimento de pertencimento a um corpo, uma profissão, uma posição hierárquica, é recolocado em causa; em que a estabilidade dos modos de pertencimento voou em explodir na direção de identidades mais contingentes e, entretanto, a empresa permanece ainda uma instância privilegiada de socialização, em direção à qual o indivíduo tem expectativas.

Ela se manifesta nos salários sob a forma de uma reclamação devido a uma falta de reconhecimento, sintoma de uma visão nebulosa sobre os modos de reconhecimento veiculado pelas regras de gestão. Com a diversificação dos pertencimentos das trajetórias profissionais, a identidade torna-se cada vez menos coletiva e cada vez mais singular, vindo a experiência substituir a determinação da posição em organização ou da categoria sócio-profissional, de onde deriva uma pesquisa intensa de uma coerência pessoal.

Além dessas, coloca-se a não menos importante questão dos pertencimentos. Como viver "o homem plural” de Bernard Lahire (2006)? Quanto mais os pertencimentos multiplicam-se e mais se trata de marcar e de saber como se apresentar segundo as diversas cenas sociais.

A questão do sentido é outra que também se apresenta aos indivíduos, reveladas dessas seções de reflexividade: que faço? Para quem você trabalha? Quais são os destinatários de sua ação?

Dessa forma, eu procuro trazer, para ele, exatamente essa questão do sentido, que, segundo Sandrine Nicourd (2005), envolve:

- o sentido para si: trata-se de encontrar os modos de ação em coerência com a sua identidade ou de reconstruir uma coerência de identidade;
- o sentido para os outros: trata-se de questionar-se sobre a utilidade social de sua ação com relação às normas da organização;

- o sentido com os outros: trata-se de pesquisar as sociabilidades portadora de reconhecimento que são os pares;

- o sentido em sua época, com relação a um mundo visado, que faria referência, gênero, geração, profissão, etc.

Como agir e criar recursos e redes? Essa, enfim, é a grande pergunta do indivíduo, ator de sua trajetória? Trata-se para ele de representar sobre várias direções antes de passar para a ação. Isso necessita tomar um tempo de parada para reler a sua trajetória, produzir uma imagem de si no mundo por uma fala como meio de transformação, depois de criar e converter os recursos e as redes em curso

\section{CONCLUSÕES: AS PERGUNTAS FEITAS À SOCIOLOGIA}

Por fim, uma reflexão necessária impõe-se, tanto sobre as hibridizações teóricas, como sobre os métodos e sobre as posturas.

\section{V.1. Os referenciais teóricos}

O que temos então poderia ser caracterizado como uma sociologia das trajetórias ao cruzamento das trajetórias bibliográficas e institucionais? As análises sociológicas abordaram a questão do processo de individualização, a ocorrência do indivíduo no seio da modernidade, assim o convite para investir a noção de trajetória impôs-se progressivamente para prestar conta da maneira pela qual um indivíduo torna-se um indivíduo por meio de provas sucessivas por preocupação de uma inteligibilidade do social, um social mais "relacional" do que "posicional”, e no cruzamento das trajetórias das firmas e dos compromissos sócio-produtivos propostos no quadro da sociologia da empresa.

Trata-se então de apoiar-se sobre uma hibridização dos referentes teóricos para prestar conta da complexidade dos vínculos sociais contemporâneos. Pode-se recorrer à análise histórica para compreender ao mesmo tempo a história da organização e a história do indivíduo na psicosociologia, para levar em conta a dimensão do atorsujeito e a noção de subjetividade para revisitar o conceito de identidade, a questão do reconhecimento, é assim necessário estabelecer ida e volta 
entre a dimensão macro e micro e entre temporalidades múltiplas.

Estaríamos então em direção a uma sociologia da experiência? Para François Dubet, o que chamamos «a sociedade" não é mais redutível a um sistema integrado, um modo de produção e a um Estado nacional. Desde então, o próprio objeto da sociologia muda: Ela deve descrever experiências sociais, quer dizer, as condutas individuais de cada um dentre nós. Essas combinam várias racionalidades e várias lógicas, elas se apresentam como a justaposição dos pertencimentos comunitários, de cálculos do mercado e de exigências de uma autenticidade individual; e o único princípio de unidade da experiência social é o trabalho sobre ele mesmo que segue cada um de nós a fim de perceber-se como o autor de sua própria vida.

\section{V.2. Os métodos}

Uma capacidade de interpretação ligada à checagem cruzada dos dados e por vezes à hibridização dos métodos. Esses objetivos pedem o uso de várias abordagens metodológicas para cruzar vários dados a fim de objetivar a análise (documentos, observações, entrevistas individuais e entrevistas de grupos). Importa para o pesquisador, ao mirar o objetivo de sua pesquisa:

- juntar elementos de conhecimento sobre um meio social ou profissional?

- compreender o sentido subjetivo de uma prática, de um itinerário comum?

- estudar uma ancoragem de identidade, etmológica, antes de fazer-se as questões de escolha de método?

\section{V.3. Uma postura clínica e crítica}

Tudo isso pode ser entendido como uma postura de escuta empática entre a armadilha da "psicologização" e a armadilha da "sociologização". O pesquisador deve desenvolver uma postura de escuta e de empatia rogeriana para ajudar na construção de uma fala ao espelho sem uma atitude de avaliação nem de sedução quando da entrevista, além de dever manter uma distância crítica ne- cessária para a interpretação que ele faz do fato. Mas como levar em conta de maneira compreensiva os indivíduos, tendo em conta esses objetivos e como acompanhar o entrevistado em sua postura de reflexividade em busca de sentido? Entrevistador e entrevistado devem evitar a armadilha da psicologização, do bate-papo, da ilusão biográfica e da sociologização, ou tudo seria determinado. Trata-se de construir uma postura ao mesmo tempo clínica e crítica.

Quais seriam enfim as expectativas para a sociologia que daqui derivam? O compromisso do sociólogo volta-se para a elucidação das situações sociais, ele contribui para articular as problemáticas de mudança, para analisar os funcionamentos coletivos e as mudanças de modos de regulação. É-lhe demandado cada vez mais levar em conta a chegada de cada indivíduo, o processo de individualização e "descoletivização" em curso e todas as questões que isso traz. Deve também trabalhar as modalidades de análise, como responder às novas expectativas sociais, como transferir os modos de análise sociológica aos atores individuais, o que, enfim, demanda-lhe ser inventivo em matéria de hibridizações teóricas, de métodos e de postura para favorecer a compreensão e a reflexividade dos atores sociais.

É a eterna questão colocada ao sociólogo e à sociologia e cujas respostas constroem-se sem parar: Qual posicionamento e qual postura adotar frente à demanda social? Qual utilidade para a sociedade e seus atores? Quais são as condições do comprometimento científico e político?

Por útimo, caberia pensar como passar do trabalho à obra, que é uma pergunta transversal. Nesse mundo mutável e contingente, há uma questão que concerne a todos, quer sejamos um gerente ou um sociólogo, que é a seguinte: qual seria a obra capaz de responder à demanda de identidade? Para Bernard Eme (2005), o reconhecimento da identidade seria doravante ligado à da trajetória pessoal e não mais à dos pertencimentos de identidade: imenso deslocamento das reivindicações de reconhecimento às quais os modos de gestão dos recursos humanos respondem tanto bem quanto mal.

Geneviève Dahan-Seltzer (genevieve.dahan-seltzer@wanadoo.fr) é pesquisadora do LISE - Laboratoire Interdisciplinaire en Sociologie Economique (CNAM-CNRS) e Professora Associada do DESS - Instituto de Estudos Políticos de Paris. 


\section{REFERÊNCIAS BIBLIOGRÁFICAS}

AUBER, N. 2004. L'individu hypermoderne. Paris : Eres.

BALANDIER, G. 1998. Le désordre, éloge du mouvement. Paris : Fayard.

CASTEL, R. \& ENRIQUEZ, E. 2008. D’où vient la psychologisation des rapports sociaux? Sociologies Pratiques, Paris, PUF, n. 17, p. 15-27.

CROZIER, M. \& FRIEDBERG, E. 1977. L'acteur et le système. Paris : Le Seuil.

DAHAN-SELTZER, G. 2008.

DUBAR, C. 2000. La crise des identités, l'interprétation d'une mutation. Paris : PUF.

DUBET, F. 1994. Sociolgie de l'expérience. Paris : Le Seuil.

EHRENBERG, A. 1998. La fatigue d'être soi. Paris : Odile Jacob

EME, B. 2005. L'existence bafouée des jeunes précaires. Revue Projet, Paris, n. 289, nov.
Disponível em : http://www.ceras-projet.com/ index.php?id=1220. Acesso em : 18.out.2008.

GAULEJAC, V. 1994. La lutte des places. Paris : Desclée de Brouwer.

GIDDENS, A., BECK, U. \& LASH, S. 1994. Reflexive Modernisation. London : Polity.

GROSSETTI, M. 2004. Sociologie de l'imprévisible, dynamiques de l'activité et des formes sociales. Paris : Presses Universitaires de France, col. "Sociologie d'aujourd'hui”.

KAUFMAN, J.-C. 2006. Dictionnaire des sciences humaines. Paris : PUF.

LAHIRE, B. 2006. L'homme pluriel, les ressorts de l'action. Paris : Nathan.

MARTUCELLI, D. 2006. Forgé par l'épreuve. L’individu dans la société contemporaine. Paris : Armand Colin.

NICOURT, S. \& DUCLOS, B. H. 2005. Pourquoi s'engager? Bénévoles et militants dans les associations de solidarité. Paris : Payot. 
Geneviève Dahan-Seltzer

Over the last few years, I have worked to develop individuals' analytical and reflexive abilities regarding modes for regulating firms undergoing processes of transformation. I have done this through groups organized to analyze practices as well as through individual and group interviews. My thesis centers around the notion that today, in the current world, individuals experience a sort of vertigo or disorientation which sends them out on a perpetual search for points of reference, resources and networks. What is disturbing in this specific case is that the trajectories of firms and individuals can unfold in a parallel manner, that is, move in the same direction for a period of time and then suddenly become antagonistic. . Thus, professional trajectories are no longer as upwardly spiraling and foreseeable as they once were. Each person must therefore engage in reflexive efforts and analyze the contexts in which he or she evolves in the building of his/her professional trajectory, with heavy consequences at stake. To be an actor in one's own trajectory is imperative both in firms and in society today and can not be understood in any isolated manner. Rather, it is a process that involves numerous questions and requires specific conditions if it is to evolve. After examining some introductory issues linked to this theme, I present the types of individual professional trajectories that I have observed in these times of crises, carrying out a final reflection on the challenges that this theoretical and practical work present to Sociology.

KEYWORDS: social regulation of firms; lost sense of orientation; professional trajectories; social and individual crisis. 


\section{Geneviève Dahan-Seltzer}

Les dernières années, je cherche à développer les capacités d'analyse et de réflexion des individus par rapport aux modes de régulation des entreprises en transformation, par l'intermédiaire de groupes d'analyse de pratiques professionnelles, d'interviews individuelles et de groupe. La thèse que je développe est que dans le monde actuel les individus expérimentent le vertige, la perte des sens et cherchent des repères, des réseaux et des ressources, dans un «mouvement perpétuel ». Ce qui dérange alors, c'est que les trajectoires des entreprises et des individus peuvent être parallèles, c'està-dire avancer dans la même direction pendant un certain temps, puis elles deviennent soudainement très antagoniques. Ainsi, les trajectoires profissionnelles ne sont guère tellement ascensionnelles et prévisibles comme elles l'étaient auparavant. Il revient à chacun de faire un effort de réflexion et d'analyser les contextes où il évolue pour construire sa trajectoire professionnelle, sous peine de retrait, sinon de rejet, avec toutes les conséquences qui en découlent. Être acteur de sa trajectoire est une injonction de l'actualité dans les entreprises et dans la société, n’ayant pas de sens de manière isolée, cette démarche implique beaucoup de questions et exige des conditions précises pour son développement. Aprés avoir examiné quelques aspects introductoires à ce thème, je présenterai ce que j’observe comme types de trajectoires professionnelles des individus dans ce contexte de crise, en menant à la fin une réflexion sur les enjeux que ce travail théorique et pratique présente à la Sociologie.

MOTS-CLÉS : régulation sociale d'entreprises ; perte de sens individuelle ; trajectoires professionnelles ; crise sociale et individuelle. 